\title{
COMPORTAMENTO ESTATÍSTICO DO GRAU DE ACIDEZ DAS CHUVAS NA CIDADE DE NATAL/RN PELA DISTRIBUIÇÃO GAUSSIANA
}

\author{
D. P. LOPES ${ }^{1}{ }^{*}$, A. E. LÍVIO' ${ }^{1}$, M. R.SOUSA ${ }^{2}$ e F.M. SILVA ${ }^{1}$ \\ ${ }^{1}$ Universidade Federal Rio Grande do Norte - UFRN \\ ${ }^{2}$ Instituto Federal do Rio Grande do Norte - IFRN \\ danielpereiralopes@live.com
}

Artigo submetido em maio/2014 e aceito em dezembro/2014

DOI: $10.15628 /$ holos.2014.2175

\section{RESUMO}

O conhecimento do comportamento do grau de acidez da precipitação pluviométrica torna-se relevante para as ciências de cunho ambiental, especialmente à Geografia, que busca entender os fenômenos provenientes da interação homem-atmosfera-paisagem. Assim, o artigo objetiva analisar o comportamento estatístico do grau de acidez das chuvas na cidade de Natal/RN. Para tanto, foram utilizados dados pluviométricos coletados na Estação Climatológica da Universidade Federal do Rio Grande do Norte/UFRN no período de 14/12/2005 a 25/08/2006, tendo como coordenadas geográficas: latitude $05^{\circ} 55^{\prime}$ Sul e longitude de $35^{\circ} 12^{\prime}$ Oeste, com uma altitude de 48,62 metros. Ao término de cada evento chuvoso, foi realizada a medição do $\mathrm{pH}$ da amostra utilizando um phgâmetro portátil de marca WTW modelo 330i com resolução de $\pm 0,003$, calibrado anteriormente a cada medição. Como método de análise fez-se uso da estatística descritiva (tendência central e dispersão) e da estatística probabilística (Distribuição de Gauss). Os resultados mostraram que a concentração do $\mathrm{pH}$ da precipitação pluviométrica de Natal/RN, apresenta uma média de 5,914, com coeficiente de variação de $8 \%$, encontra-se em níveis preocupantes, pois, a taxa de concentração está abaixo dos limites que segundo a Resolução do CONAMA 357/2005.

PALAVRAS-CHAVE: Chuvas ácidas; Sistema sinótico; Ambiente; Potencial Hidrogeniônico-pH.

\section{STATISTICAL BEHAVIOUR OF LEVEL OF ACID RAIN IN THE CITY OF NATAL/RN BY GAUSSIAN DISTRIBUTION}

\begin{abstract}
The knowledge of the behavior of the degree of acidity of rainfall becomes relevant to the sciences of environmental nature, especially to Geography, which seeks to understand phenomena from human-Catmosphere interaction. Thus, the article objective analyze the statistical behavior of the degree of acidity of rainfall in Natal/RN. Thus, the paper objective analyze the statistical behavior of the degree of acidity of rainfall in Natal/RN. For this, we used rainfall data collected in the Climatological Station of the Federal University of Rio Grande do Norte/UFRN the period 14/12/2005 to 25/08/2006 For both, having as geographical coordinates: latitude $05^{\circ} 55^{\prime}$ South and longitude $35^{\circ} 12^{\prime}$
\end{abstract}

West, at an altitude of $\mathbf{4 8 . 6 2}$ meters. At the end of each rainfall event, the measurement of $\mathrm{pH}$ was carried out using a portable WTW phgâmetro model 330i brand with resolution of $\pm 0,003$, calibrated before each measurement. As a method of analysis was done using descriptive statistics (central tendency and dispersion) and probabilistic statistical (Gaussian distribution). The results showed that the concentration of the $\mathrm{pH}$ of rainfall in Natal/RN. has an average of 5,914, with a coefficient of variation of $8 \%$, is at worrying levels, therefore, the concentration ratio is below the limits according to CONAMA Resolution 357/2005.

KEYWORDS: Acid Rain; Synoptic System; Environment; Potential-pH Hydrogenionic. 


\section{INTRODUÇÃO}

A produção de gases que modificam o pH da água e que são jogados na atmosfera, surge no auge da chamada Revolução Industrial na Inglaterra durante o século XVIII, pois foi um marco de revolução social, onde mudaram-se as bases técnicas de extração, produção, distribuição e consumo na sociedade. Esse momento é marcado por várias mudanças nas relações sociais, avanços científicos e tecnológicos, o que possibilitou uma maior produção em larga escala e consequentemente maiores índices de poluição atmosférica, ou seja, houve uma grande transformação da natureza para suprir as necessidades humanas através das mudanças das bases técnicas para se usufruir da biodiversidade disponível no planeta. A questão da acidificação vemse agravando cada vez mais nas últimas décadas, constituindo-se em problema de natureza ecológica em várias regiões onde haja grandes aglomerações urbanas e/ou centros industriais.

Com isso, o lançamento de compostos de enxofre e nitrogênio na atmosfera provenientes das indústrias, veículos automotivos levam a oxidação dos mesmos formando nitratos e sulfatos, que são os principais causadores do fenômeno conhecido como chuva ácida, que provem da ação antrópica desde o período da revolução industrial e, por conseguinte pela forma desacerbada de ocupação urbana, e segundo ALVES, ALVES e SILVA (2009).

O intenso processo de urbanização e industrialização tem colocado em risco a qualidade de vida dos habitantes das áreas urbanas, risco este, relacionado com o ar que se respira nas cidades. O aumento da frota de veículos, associados a fatores meteorológicos como a temperatura do ar, pressão e umidade, têm contribuído para com a concentração de poluentes em suspensão na atmosfera, gerando um clima urbano poluído e propício a desencadear diversos tipos de doenças aos habitantes dos grandes centros urbanos.

Nesta perspectiva, a poluição ambiental causada pela chuva ácida aumenta a solubilização de metais tóxicos, pois, há um acréscimo das concentrações de alumínio, cádmio, chumbo e mercúrio na água. Em contra partida a acidez da água pode ser corrigida, visto que ela também é causada pela ação do homem. Essa correção é feita através do método também como enfatiza TAVARES, (2009).

Quando o ar atmosférico está desprovido de poluentes, o único ácido que influência no potencial hidrogeniônico $(\mathrm{pH})$ das chuvas é o ácido carbônico. Esse ácido, dissolvido na água pura, mantém o $\mathrm{PH}$ das águas pluviais levemente ácidos, com valores pouco abaixo de 5,65. O dióxido de enxofre (SO2) representa o principal elemento responsável pela acidez das chuvas, um fragmento do ácido sulfúrico cujo odor é extremamente desagradável além de perigoso à saúde humana.

Assim, as gotas d'água quando precipitadas trazem consigo a água em estado de oxigenação e ácidos em suspensão na atmosfera como: sulfúrico, nítricos, acéticos e fórmicos, além do sulfato e nitrato de amônia na sua composição. Nesta perspectiva, a formação da chuva ácida é resultante da produção e emissão de gases, provenientes da natureza e da ação antrópica, como, dióxido de enxofre e óxidos de nitrogênio, que são lançados na baixa atmosfera. Sendo assim, Melo (2007), enfatiza que quando o potencial hidrogeniônico-pH da água se torna 
baixo (condições ácidas), ela provoca corrosão e, quando o pH é alto (condições básicas) pode provocar incrustações, ou seja, o acumulo de ferrugem dos metais.

Isso é o que vem se configurando nas cidades urbanizadas na atualidade, devido a vários fatores e um deles é o adensamento de veículos de forma desordenada, fazendo que nas cidades, além da poluição das indústrias, adensamento populacional, os agentes causadores da chuva ácida se intensifiquem chegando a aumentar os riscos para a saúde humana, como bem afirma (MEIRELES apud SOUZA, 2010):

A concentração populacional, as indústrias, o comércio, os veículos motorizados e até a agricultura e a pecuária produzem alterações no meio ambiente. Essas alterações, quando normais e toleráveis, não merecem contenção e repressão, só exigindo combate quando se tornam intoleráveis e prejudiciais à comunidade, caracterizando poluição reprimível.

Com isso, a acidificação da chuva é derivada de fenômenos naturais e antrópicos, que para a sociedade os efeitos são econômicos, visto que a chuva vem atingir monumentos públicos e históricos, danificando os mesmos. Sobre este aspecto (GOLDEMBERG \& VILLANUEVA, 2003) ressaltam que: uma forma de medir a acidez de um líquido é avaliando a concentração de íons de hidrogênio que ali existe em unidades de $\mathrm{pH}$, onde está concentração é representada como um logaritmo negativo (de base 10). Varia de 0 a 14, sendo que, o valor 7 representa um valor neutro, tal como pH da água pura.

Sobre isso, (ALMEIDA \& RIGOLIN, 2003) ressalta que:

Na natureza, existe uma harmonia nas relações entre os seres vivos, entre si e entre os seres vivos e o meio ambiente. É o chamado equilíbrio ecológico. Ao quebrar essa harmonia, o homem provoca o que chamamos de impacto ambiental.

Nesta perspectiva, o potencial hidrogeniônico ou pH é definido como o negativo do logaritmo na base 10 da concentração dos íons hidrogênio, tendo variação entre 0 e 14 (limite ácido/limite alcalino), com o valor 7 representando a condição neutra. Em águas e efluentes líquidos, bem como na digestão anaeróbia, o controle do $\mathrm{pH}$ é fundamental. $\mathrm{O} \mathrm{pH}$ da maioria das águas naturais encontra-se entre 6,0 e 8,5, embora valores menores possam ocorrer em águas com alto conteúdo orgânico diluído. Em esgotos sanitários, o pH normalmente está compreendido na faixa 6,5 - 7,5.

Para tal veracidade das taxas de concentrações, o Conselho Nacional de Meio Ambiente (CONAMA 357) de (2005) considera que: o controle da poluição está diretamente relacionado com a proteção da saúde, garantia do meio ambiente ecologicamente equilibrado e a melhoria da qualidade de vida, levando em conta os usos prioritários e classes de qualidade ambiental exigidos para um determinado corpo de água, isso de acordo com o art. 1‥

Esta resolução dispõe sobre a classificação e diretrizes ambientais para o enquadramento dos corpos de água superficiais, bem como estabelece as condições e padrões de lançamento de efluentes. E ainda, esta mesma resolução, estabelece que águas das Classes Especial, I e II, são destinadas, entre outros, à preservação da vida aquática (artigo 4ㅇ) , e estipula que a faixa de pH para essas Classes deve ser de 6,0 a 9,0. Nesse contexto, o artigo objetiva analisar o 
comportamento estatístico, descritivo e probabilístico, do grau de acidez das chuvas na cidade de Natal/RN.

\section{MATERIAIS E MÉTODOS}

A região a ser estudada é o município de Natal/RN. Este está situado na região Nordeste do Brasil, na porção leste do Estado, sua região metropolitana conta com uma população em torno de 803.739 mil habitantes (IBGE 2010). Situando-se a $5^{\circ} 45^{\prime} 54^{\prime \prime}$ de latitude sul e $35^{\circ} 12^{\prime} 05^{\prime \prime}$ de longitude oeste com posição intertropical no hemisfério sul.

O trabalho teve como base metodológica, a aquisição de dados pluviométricos advindos da Estação Climatológica da Universidade Federal do Rio Grande do Norte/UFRN, bem como o potencial hidrogeniônico $(\mathrm{pH})$ da precipitação no período de 14/12/2005 a 25/08/2006. Fez-se necessário o uso da estatística descritiva (tendência central, quartis e dispersão) e seu comportamento probabilístico pela Distribuição de Gauss.

\section{RESULTADOS E DISCUSSÃO}

A estatística descritiva, Tabela 1, mostra que o $\mathrm{pH}$ da precipitação apresenta uma média de 5,914, mediana de 5,790 e uma moda de 6,102, apresentando um desvio padrão de 0,474 e pouca variabilidade $(\mathrm{CV}=8,019 \%)$. As medidas de tendência central interrelaciona-se com pouco desvio, assim elas apontam para um pH em conformidade com a resolução 357 do CONAMA.

Tabela 1: Estatística descritiva do pH da precipitação em Natal/RN.

\begin{tabular}{|l|r|}
\hline Média & 5,914 \\
\hline Mediana & 5,790 \\
\hline Moda & 6,102 \\
\hline Desvio padrão & 0,474 \\
\hline Coeficiente de Variação - CV (\%) & 8,019 \\
\hline
\end{tabular}

Fonte: PROPESQ/UFRN, 2005-2006.

Analisando os dados como uma única amostra, verifica-se que não há acidez no $\mathrm{pH}$ da precipitação em Natal/RN. Entretanto dividindo-se em sub-amostras, conforme atuação dos sistemas sinóticos (nuvens com perfil dinamicamente organizadas) em Natal/RN é possível verificar que tem diferenças significativas.

A Figura 1 mostra o comportamento dos sistemas sinóticos atuantes na cidade de Natal/RN, frente ao grau de acidez das chuvas oriundas desses sistemas. Para tal, foram analisados os seguintes sistemas sinóticos: (CC) Convecção Cúmulos, (OL) Ondas de Leste, (VCAS) Vórtice Ciclônico da Atmosfera Superior (VCAS) e (ZCIT) Zona de Convergência Intertropical, conforme classificação de ALVES (2009). 


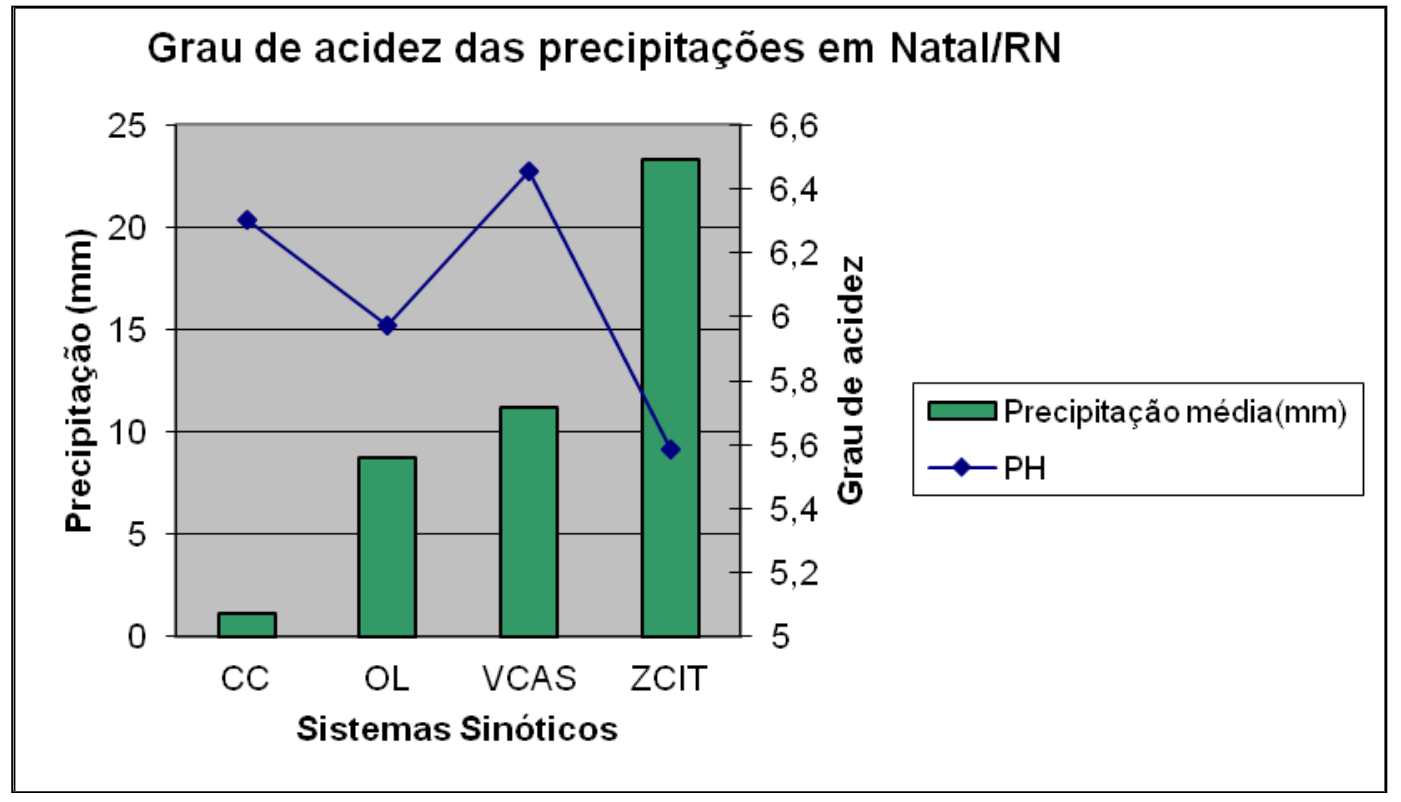

Figura 1 - Grau de acidez das chuvas em Natal/RN, conforme atuação de sistemas sinóticos.

A partir das análises dos sistemas sinóticos acima, podemos verificar que o maior índice de acidez da água da chuva na cidade de Natal/RN encontra-se na ZCIT, com pH equivalendo a 5,584, podendo-se afirmar, segundo a Resolução do CONAMA 357 (águas doces o índice de acidez deverá ficar entre 6,0 e 9,0), que o pH é pouco ácido. No entanto, as menores concentrações do potencial hidrogeniônico é encontrado VCAS, com cerca de 6,458 tornando-se básico segundo a resolução de 357 do CONAMA.

Assim, a atmosfera local não apresenta indícios de acidificação, enquanto que a atmosfera global apresenta um grau de acidez considerável, visto que a ZCIT é um sistema de nuvens que depende do comportamento global da atmosfera.

Uma análise de correlação da precipitação com o pH mostrou uma correlação inversa ($0,75)$, corroborando com o gráfico da Figura $1,0 \mathrm{pH}$ mais baixo apresenta-se quando concomitantemente o nível (concentração) da precipitação também é maior, pois, na Zona de Convergência Intertropical/ZCIT a precipitação média é de $23,3 \mathrm{~mm}$ e pH de 5,584, enquanto que no Vórtice Ciclônico da Ar Superior/VCAS a precipitação média é de 11,2 mm, com pH de 6,458.

A pesquisa identificou que, a concentração média do $\mathrm{pH}$ da precipitação pluviométrica de Natal/RN $(5,914)$, encontra-se em níveis inquietante, a taxa de concentração está abaixo dos limites que segundo a Resolução do CONAMA 357 (águas doces onde índice de acidez deverá ficar entre 6,0 e 9,0), apresentando-se assim, uma precipitação pouco ácida.

A estatística descritiva demonstrou que é pertinente (assimetria $=0,19)$ modelar os dados pela distribuição Gaussiana.

A tabela 2 mostra a probabilidade do $\mathrm{pH}$ conforme o comportamento dos quartis. Há uma probabilidade de $18,65 \%$ de ficar entre 5,535 e 5,790, intervalo correspondente ao pH da ZCIT; uma probabilidade de 16,14\% de ocorrer um pH entre 6,316 e 6,836, intervalo do VCAS, entretanto há probabilidade maior ocorreu no quartil 3, cuja intermitência varia de 5,791 a 6,315 . 
Tabela 2 - Probabilidade do grau de acidez conforme a Distribuição Gaussiana.

\begin{tabular}{|ccc|}
\hline Quartil & pH & Probabilidade (\%) \\
Q1 & 5,534 & 17,31 \\
Q2 & 5,790 & 18,65 \\
Q3 & 6,315 & 39,86 \\
Q4 & 6,836 & 16,14 \\
\hline
\end{tabular}

Analisando a amostra como um todo e aplicando os intervalos proposto pelo CONAMA, verifica-se que o grau de acidez da precipitação pluviométrica na cidade de Natal, apresenta uma probabilidade de $94,41 \%$ de ficar entre 5,021 e 6,836 ; uma probabilidade de $39,78 \%$ de ficar entre 6,000 e 9,000 , porém o mais preocupante é que há uma probabilidade de $54,63 \%$ de ocorrer precipitação com acidez entre 5,021 e 6,000. Com isso, o modelo probabilístico gaussiano mostrou que, o potencial hidrogeniônico da precipitação pluviométrica em Natal/RN vem chegando a níveis preocupantes, dentro dos padrões da resolução do CONAMA 357 de 2005.

Desta forma, a problemática da poluição do ar que ocasiona a chuva ácida, deve ser encarada como assunto socioambiental de ordem pública, assim cabe aos governantes detentores do Poder Público atuar com medidas mitigadoras para minimizar os impactos ocasionados pelo advento das chuvas ácidas na cidade de Natal/RN.

\section{CONSIDERAÇÕES FINAIS}

A atmosfera local não apresenta indícios de acidificação, enquanto que a atmosfera global apresenta um grau de acidez considerável, visto que a Zona de Convergência Intertropical-ZCIT é um sistema de nuvens que depende do comportamento global da atmosfera.

A concentração do $\mathrm{pH}$ da precipitação pluviométrica de Natal/RN, média de 5,914, encontra-se em níveis preocupantes, pois, a taxa de concentração está abaixo dos limites que segundo a Resolução do CONAMA 357 (águas doces onde índice de acidez deverá ficar entre 6,0 e 9,0), apresentando-se assim, uma precipitação pouco ácida.

Há uma probabilidade de 54,63\% de ocorrer precipitação com acidez entre 5,021 e 6,000 na cidade de Natal/RN.

Nesta perspectiva, tornar-se prioridade as políticas de gestão pública, uma vez que a ocorrência de chuva ácida é um problema que causa danos à população advindo da contaminação dos corpos d'água. Sendo assim, o estudo do comportamento do pH da chuva na cidade de Natal/RN, mostra o quanto é importante sua importância e põe em questão o futuro do abastecimento de água potável na cidade em jogo, pois se não encontrarmos outras alternativas ficaremos submissos as condições geradas pela relação homem-atmosfera-paisagem, sendo este estudo não somente para o consumo humano, mas também como uma ferramenta de planejamento urbano.

\section{REFERÊNCIAS BIBLIOGRÁFICAS}

1. ALVES, A. E. L., Monitoramento da qualidade das águas de chuvas conforme a atuação dos 
sistemas sinóticos na cidade de Natal/RN, 2009. Programa de Pós-Graduação e Pesquisa em Geografia - PPGe - UFRN, 2009.

2. ALVES, K. M.S, ALVES, A. E. L., SILVA, F. M. Poluição do ar e saúde nos principais centros comerciais da cidade de Natal/RN. Natal, Holos, ano 25, vol. 4, p.82.

3. ARAÚJO, F, Frota de carros do RN tem crescimento de 526,81\%. Tribuna do Norte. Natal, p. 0-1. 24 de julho de 2012. Disponível em: http://tribunadonorte.com.br/noticia/frota-decarros-do-rn-tem-crescimento-de-526-81/162102. Acessado em: 02/01/2014.

4. BAIRD, C. Química Ambiental. Segunda Edição. Porto Alegre: Bookman, 2002.

5. BRASIL. Resolução Conama, no 357, de 17 de março de 2005. Dispõe sobre a classificação dos corpos de água e diretrizes ambientais para o seu enquadramento, bem como estabelece as condições e padrões de lançamento de efluentes, e dá outras providências. Resolução Conama 357. Brasil, 18 mar, 2005, p. 58-63.

6. CONGRESSO NORTE NORDESTE DE PESQUISA E INOVAÇÃO, VII, 2012, Palmas. Mensuração das emissões de poluentes atmosféricos de origem veicular da cidade de Natal. Palmas: CONEPPI, 2012. 6 p. Disponível em: <http://propi.ifto.edu.br/ocs/index.php/connepi/ vii/paper/viewFile/4768/2381>. Acesso em: 15/03/2014.

7. FADINI, P. S. Quantificação de carbono dissolvido em sistemas aquáticos, através da análise por injeção em fluxo. Campinas, 1995. Dissertação de mestrado-Faculdade de Engenharia Civil-Universidade Estadual de Campinas, 1995.

8. GERHARDSSON, L., OSKARSSON, A., SKERFVINGA, S., Chuva Ácida - efeitos sobre oligoelementos e a saúde humana. São Paulo, Senac, Revista de Saúde, Meio Ambiente e Sustentabilidade 2012. Volume 7. Acesso em: <http://www.revistas.sp.senac.br/ index.php/ITF/ article/viewFile/254/229> Acessado em: 08/03/2014.

9. NOGUEIRA, I. Chuva ácida. Disponível em: <http://artigos.netsaber.com.br/resumo_artigo _39178/artigo_sobre_chuva_Ácida>. Acesso em: 20/03/2014.

10. SOUZA, D. C. O meio ambiente das cidades. São Paulo: Editora Atlas S.A. 2010. 